\title{
Decodificando o Controle Remoto com a Placa de Som do PC
}

\author{
(Decoding the TV remote control with a PC sound card) \\ Wictor C. Magno e Erivaldo Montarroyos* \\ Departamento de Física, \\ Universidade Federal de Pernambuco, \\ 50670-901 Recife, PE, Brasil
}

Recebido em 30 de setembro, 2002. Aceito em 25 de outubro, 2002.

\begin{abstract}
Analizamos neste trabalho a decodificação do controle remoto de aparelhos de TV, utilizando a placa de som de um microcomputador. O sinal codificado no infravermelho é recebido por um sensor óptico e enviado ao canal de entrada da placa de som de um microcomputador. O dispositivo de mídia é utilizado como um conversor analógico - digital (A/D) de baixo custo e de grande eficiência para sinais alternados de baixa freqüência. Um software didático foi utilizado para simular no computador um osciloscópio virtual, permitindo observar na tela do PC o sinal emitido pelo controle remoto, e decodificar algumas de suas funções de controle. A construção do aparato é de fácil acesso e muito econômica, abrindo possibilidades de ensino para estudantes do ensino médio e dos ciclos básicos do ensino superior.
\end{abstract}

In this work we analyzed the decoding of the TV remote control using a PC sound card. The infrared coded signal is received by an optical sensor and is sent to the line-in channel of the PC sound card, which is used as an analogical-digital converter (A/D) of low cost and high efficiency for low frequency AC signals. A didactic software was used to simulate in the computer a virtual scope, allowing to observe in the PC screen the emitted signal by the remote control and to decode some of its control functions. The construction of the apparatus is easy, very economic, and opening teaching possibilities for high school students and undergraduates.

\section{Introdução}

Entender a Física de como as coisas funcionam é uma tarefa bastante interessante para os estudantes, além de ser uma grande aliada do professor no processo ensinoaprendizagem, pois relaciona conceitos didáticos à experiência diária dos estudantes, favorecendo assim a construção do conhecimento de forma lúdica e integrada. No nosso dia-a-dia há inúmeras possibilidades de exemplificação dos conceitos fundamentais da Física para estudantes de ensino médio ou dos ciclos básicos do ensino superior, baseando-se na utilização de utensílios domésticos e de domínio público. Podemos, por exemplo, introduzir conceitos básicos de Mecânica Quântica observando a chama amarela de uma porção de sal de cozinha em um fogão ou em um bico de Bunsen, ou então olhando para as lâmpadas de vapor de sódio da iluminação pública. Como outros exemplos, podemos apresentar fundamentos básicos da Termodinâmica, explicando o funcionamento de uma garrafa térmica, de um refrigerador ou de uma panela de pressão. Recen- temente, a decodificação das funções de um controle remoto de TV [1] mostrou-se bastante simples para explorar vários conceitos de Eletromagnetismo como demonstração da lei do inverso do quadrado da distância $\left(1 / r^{2}\right)$, aplicação de dispositivos semicondutores, tecnologia fotônica, sistema binário de transmissão de informações, dentre outros. Neste trabalho, o autor utilizou uma interface comercial de aquisição de dados conectada ao PC para decodificar algumas funções de um controle remoto de TV. Apresentamos neste trabalho a decodificação do controle remoto utilizando unicamente a placa de som de um microcomputador como sistema de aquisição de dados, sem a necessidade de qualquer outra interface de aquisição, e por um custo significativamente inferior ao utilizado na Ref. 1.

O sinal produzido pelo controle remoto é emitido por um diodo emissor de luz ( $L E D)$ no infravermelho $(I R)$ e pode ser recebido a longa distância por um sensor óptico. Este sinal elétrico (analógico) é então enviado ao canal de entrada (line-in) da placa de som, a qual é utilizada como um conversor analógico - digital

*erimont@df.ufpe.br 
(A/D) de baixo custo e de grande eficiência para sinais eletrônicos alternados de baixa freqüência [2]. Podemos observar em tempo real as seqüências de pulsos enviados pelo controle, olhando na própria tela do PC, através de um software didático [3] que transforma o computador em um osciloscópio virtual de dois canais.

\section{Medindo a seqüência de pul- sos do controle remoto}

O procedimento para aquisição de dados do controle remoto com a placa de som do computador é extremamente simples e será pormenorizado a seguir. Antes de tudo, o microcomputador deverá possuir uma placa de som devidamente instalada com seus softwares de controle. Em seguida, o programa Winscope [3] deve ser executado. Deve-se também dispor de um cabo de som estéreo ( $1 / 8$ de polegada) com conector macho, a fim de acoplar o sinal exterior vindo do sensor óptico ao canal de entrada (line-in) da placa de som, disponível na parte de trás do gabinete do computador. Somente um dos canais do conector estéreo (incluindo o terminal comum ou o terra do cabo), será necessário para a aquisição de dados [2]. Para converter a luz emitida pelo $L E D$ do controle remoto em sinal eletrônico, devese usar um fototransistor ou pode-se usar o próprio sensor de $I R$ dos televisores para detecção dos pulsos. Este último dispositivo é muito barato e normalmente é encontrado em casas de componentes eletrônicos. Optamos neste trabalho em usar o próprio sensor de $I R$ dos televisores. Este sensor é um dispositivo semicondutor que converte os fótons no $I R$ do $L E D$ do controle remoto em elétrons na banda de condução do dispositivo, permitindo gerar uma pequena corrente elétrica suscetível de transportar a seqüência de pulsos da luz incidente, e portanto transmitir informação. Em geral este dispositivo é conhecido como um conversor de luz em tensão, como por exemplo o T.I. TSL 250, sendo encontrado encapsulado comercialmente. Após a remoção da capa de proteção do sensor, três terminais estão visíveis, da esquerda para a direita de sua parte frontal: terra, tensão de alimentação $V_{c c}$, e sinal gerado a ser enviado ao canal line-in da placa de som. A tensão $V_{c c}$ poderá variar entre $+3 \mathrm{~V}$ a $+9 \mathrm{~V}$. Uma possibilidade é usar uma tensão $V_{c c}=5 V$, tirada da própria fonte do $\mathrm{PC}$ [2].

Com um pequeno esforço de construção e com custo mínimo pode-se dispor de um decodificador de controle remoto bastante eficiente, uma vez que os sinais do controle remoto são emitidos seqüencialmente em uma frequiência baixa de dezenas de pulsos por segundo (dezenas de Hertz) e podem ser capturados facilmente pela placa de som do PC. Na Fig. 1 mostramos algumas sequiências de pulsos, típicas de um controle remoto da Sony, as quais transportam as informações respectivas do botão de controle, através da combinação entre pulsos unitários (finos) e pulsos duplos (largos), os quais podem formar uma palavra em binário considerandose a razão on-off (0 e 1) percebida pelo detector de $I R$. Essa informação é então interpretada pelo circuito receptor do TV, realizando logo após a operação desejada. Na seqüência da Fig. 1, de cima para baixo, temos as seguintes funções para as teclas: liga/desliga, abaixa volume, tecla mudo e canal 8. Podemos observar várias seqüências compostas por doze (12) pulsos, correspondendo a algumas funções de controle usuais. É importante salientar que essas seqüências de pulsos variam de acordo com o modelo do controle remoto em uso.

\section{Conclusão}

Em resumo, discutimos a decodificação das funções de um controle remoto de TV utilizando um sistema de aquisição de dados de baixo custo, baseado no conversor analógico/digital da placa de som do computador. Como na maioria dos computadores pessoais modernos a placa de som já vem incluída on-board, o custo do presente sistema de aquisição é extremamente baixo. Apresentamos algumas seqüências de pulsos típicas de um controle remoto, identificando suas funções de controle. $\mathrm{O}$ presente sistema permite a realização de vários experimentos simples de Eletromagnetismo para estudantes do ensino médio e dos ciclos básicos do ensino superior, e abre novas possibilidades de ensino-aprendizagem a um custo bastante reduzido.

Apoio Financeiro: CNPq.

\section{Referências}

[1] James O'Connell, The Physics Teacher 38, 6 (2000).

[2] Erivaldo Montarroyos e Wictor C. Magno. Revista Brasileira de Ensino de Física 23 (1), 57 (2001).

[3] "Oscilloscope for Windows95", version 2.51. Copyright (C) Konstantin Zeldovich: zeld@polly.phys.msu.su. Este programa didático transforma o PC em um osciloscópio virtual e em um analisador de espectro. Disponível gratuitamente somente para fins didáticos em: http://www.df.ufpe.br/wcm. 


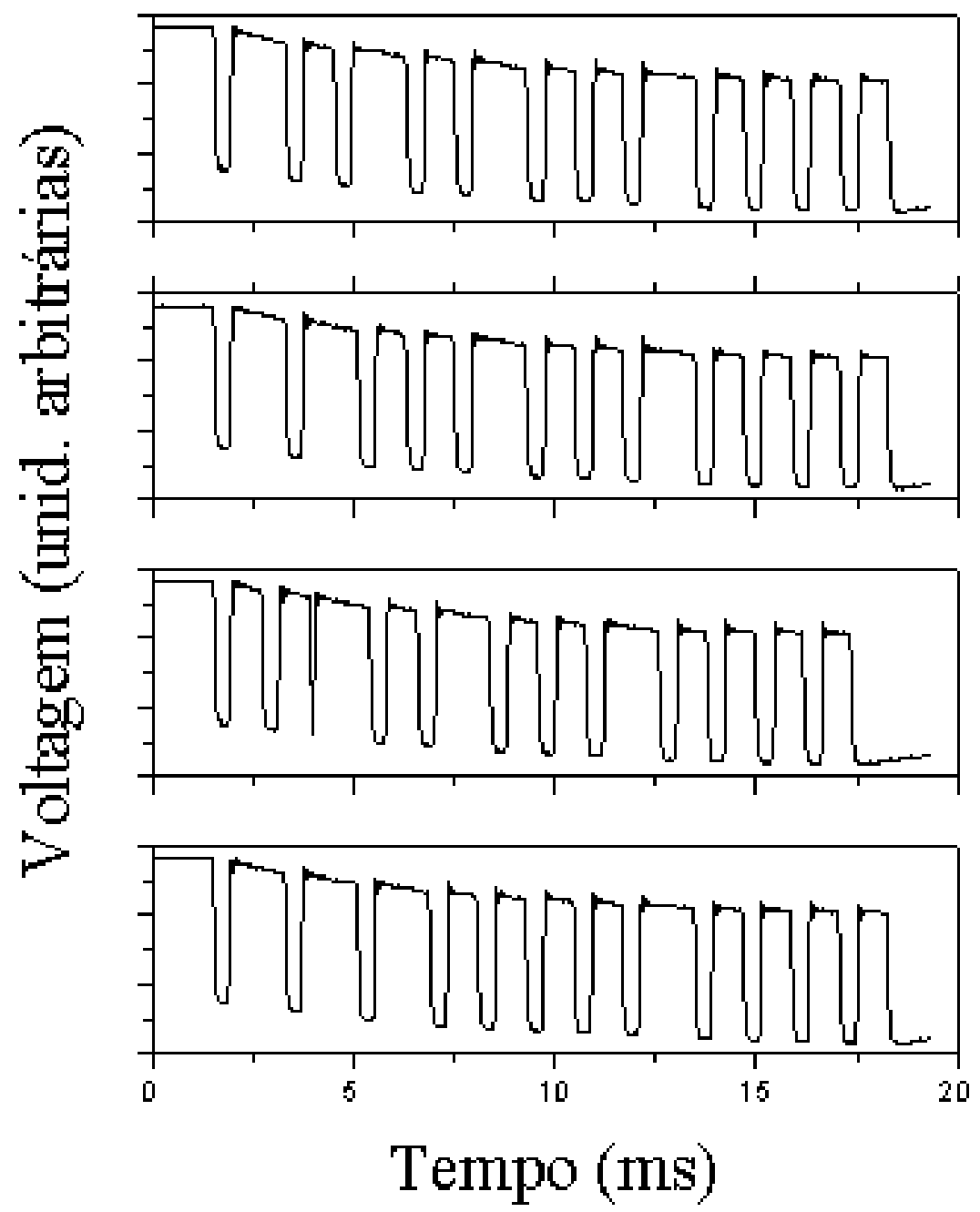

Figura 1. Seqüências temporais de pulsos emitidos por um controle remoto de TV, capturadas com um sensor de infravermelho acoplado a entrada de som (line-in) de uma placa de som de um microcomputador. Na ordem decrescente, temos as seguintes funções de controle: chave liga/desliga, abaixa volume, tecla mudo e canal 8. 